Terr. Atmos. Ocean. Sci., Vol. 17, No. 3, 489-502, September 2006

\title{
Area Balancing Method as a Useful Tool to Estimate the Depth of the Chi-Chi Earthquake Rupture at the Fengyuan Well
}

\author{
Yuan-Hsi Lee ${ }^{1, *}$, Shih-Ting Lu ${ }^{2}$, Tung-Sheng Shih ${ }^{2}$ \\ (Manuscript received 15 June 2004, in final form 1 June 2006)
}

\begin{abstract}
The 1999 Chi-Chi earthquake, $M_{w}=7.6$, was associated with a near 100-km-long surface rupture along which the horizontal slip and vertical displacement reached to $9 \mathrm{~m}$ and $4 \mathrm{~m}$, respectively, according to coseismic GPS slip vectors. After the Chi-Chi earthquake, drilling projects were conducted to clarify the characteristics of the earthquake rupture in depth. At the Fengyuan site, inclined-well drilling was performed at an angle of 50 degrees westward to a drilling depth of $\mathbf{4 5 5 . 3} \mathrm{m}$ in the northern segment of the Chi-Chi earthquake rupture. Two possible earthquake rupture zones were observed at drilling depths of $225 \mathrm{~m}$ and $330 \mathrm{~m}$ according to the core structures and seismic profiling. We apply an area balancing method to determine the depth of the earthquake rupture in the cores; and we suggest that the 330-m drilling depth is the most likely candidate for the earthquake rupture.
\end{abstract}

(Key words: Chelungpu fault, Area balancing method,

Chi-Chi earthquake, Fengyuan well)

\section{INTRODUCTION}

The 21 September, 1999 Chi-Chi earthquake $\left(M_{w}=7.6\right)$, a consequence of the on-going collision between the Philippine Sea plate and Eurasian plate (Fig. 1), produced a surface rupture about $100 \mathrm{~km}$ long in western Taiwan. At the northern segment near the Shihkang area, the rupture has a throw of up to $10 \mathrm{~m}$, the largest coseismic displacement ever docu-

\footnotetext{
${ }^{1}$ Department of Earth and Environmental Sciences, National Chung Cheng University, Chia-Yi, Taiwan, $\mathrm{ROC}$

${ }^{2}$ Central Geological Survey, MOEA, Taiwan, ROC

* Corresponding author address: Dr. Yuan-Hsi Lee, Department of Earth and Environmental Sciences, National Chung Cheng University, Chia-Yi, Taiwan, ROC; E-mail: seilee@eq.ccu.edu.tw
} 
(a)

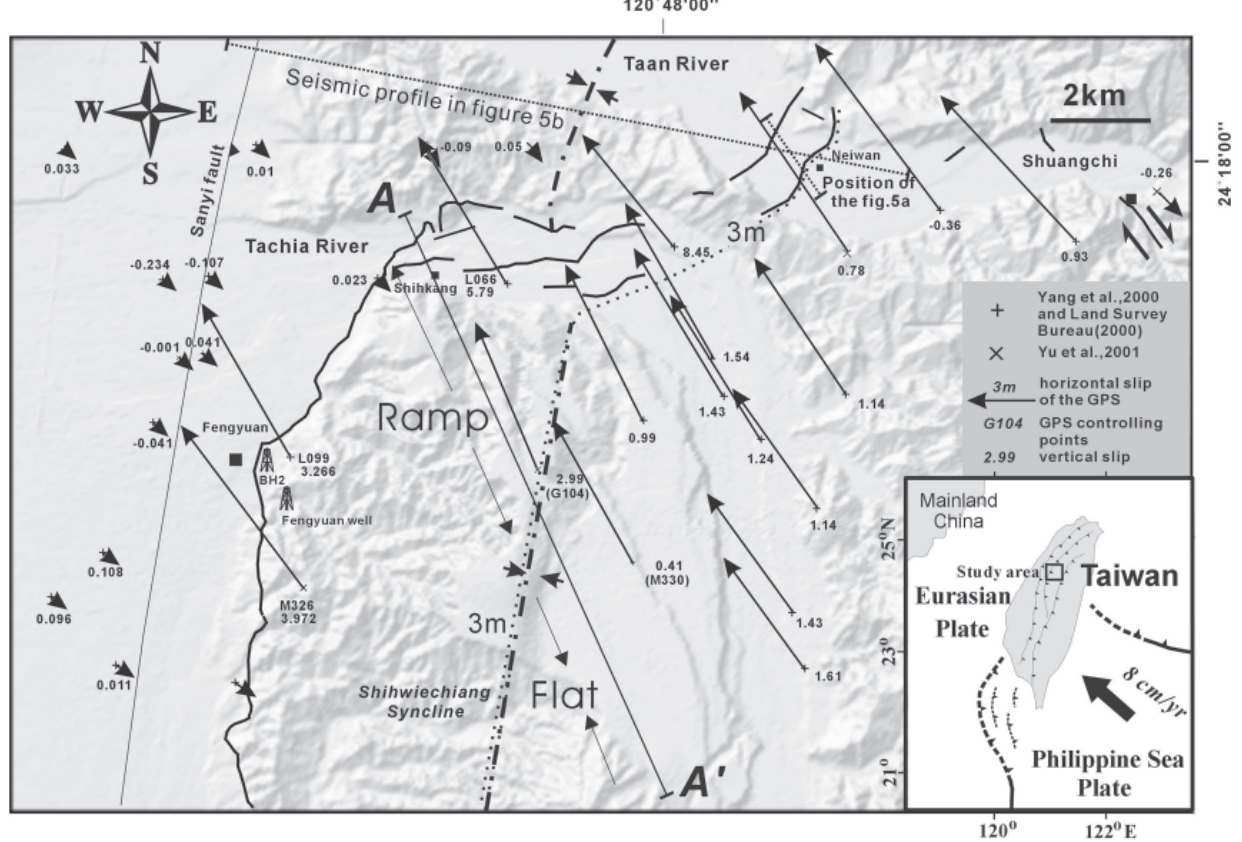

(b)

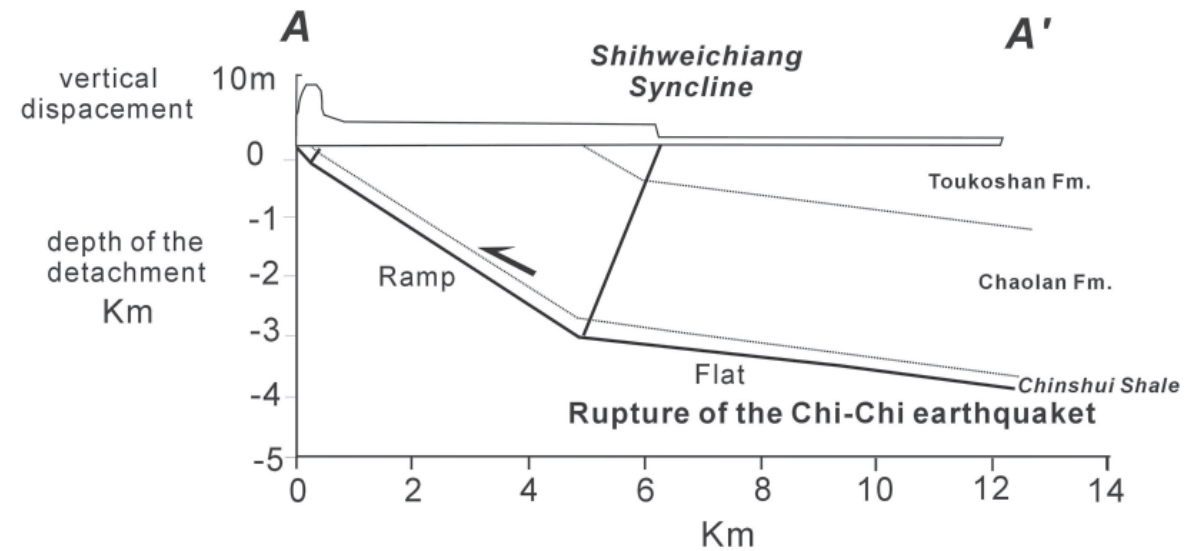

Fig. 1. (a) Horizontal and vertical displacements of the GPS at the northern segment of the Chi-Chi earthquake. (b) In the northern segment of the Chi-Chi earthquake, the rupture of Chi-Chi earthquake shows a rampflat structure (Lee et al. 2005). The vertical displacement is larger than $3 \mathrm{~m}$ on the ramp plane and near $1 \mathrm{~m}$ on flat plane. 
mented on a reverse fault (Chen et al. 2001a; Yu et al. 2001) (Fig. 1). The Chi-Chi earthquake was caused by a slip along the Chelungpu fault, a major thrust fault in the frontal fold-andthrust belt of western Taiwan.

After the Chi-Chi earthquake, many drilling projects and trenching studies have been conducted to analyze the characteristics of the rupture of the Chi-Chi earthquake (Chen et al. 2004). For example, drilling projects have been conducted at both the Fengyuan and Nantou areas (Wang et al. 2000, 2002). At the Nantou site, the drilling well successfully penetrated the fault at around a depth of $177 \mathrm{~m}$ (Tanaka et al. 2002). In this well, the position of rupture in the core is easily recognized by different strata in the footwall and hanging wall. At the Fengyuan site, the drilling was performed as an inclined well at an angle of 50 degrees westward (Fig. 6). It appears to penetrate possible earthquake rupture zones at drilling depths of $225 \mathrm{~m}$ and $330 \mathrm{~m}$ (Tanaka et al. 2002). According to shallow seismic reflection studies and core structures, the 225-m drilling depth was considered the position of the Chi-Chi earthquake slip plane (Tanaka et al. 2002). However, some researchers consider the 330-m drilling depth to be the actual position of the slip plane rupture based on the fracture density distribution of the fault zone (Heermance et al. 2003). This ambiguity results from the facts that both the hanging wall and footwall of the Chi-Chi earthquake rupture have similar strata at the Fengyuan site, and that the existence of many fractures increases the difficulty in identifying the Chi-Chi earthquake slip plane. Identifying the position of the slip surface in the drilling core has become a key issue; and this represents one of the main targets of this study. This research utilizes the area balancing method to better identify the depth of the slip plane. As a result, we suggest that the position of the earthquake slip plane at the Fengyuan well is at the 330-m drilling depth.

\section{GEOLOGICAL BACKGROUND}

The Chelungpu fault is a major thrust fault in the western foothills of Taiwan where the Pliocene to Miocene strata thrust over on the Pleistocene Toukoshan Formation with a tenkilometer net separation (Fig. 2) (Chang 1971). In a strict sense, only the middle to southern segments of the Chi-Chi earthquake rupture follows the surface trace of the Chelungpu fault. At the northern segment, the rupture does not follow the Chelungpu fault, but rather a new fault that is a bedding slip along the Chinshui Shale (Fig. 2) (Chen et al. 2001b; Lee et al.2000; Lee et al. 2003a; Lee et al. 2005).

At the northern segment, to the north of Wufeng, the subsurface structure of the Chi-Chi earthquake fault shows a ramp-flat structure with vertical displacement of more than $3 \mathrm{~m}$ on the ramp plane and less than $1 \mathrm{~m}$ vertical displacement on the flat plane (Fig. 1) (Lee et al. 2005). The ramp plane is located from the western side of the Shihweichiao syncline axis to the surface rupture. The strata strikes roughly N-S with $40^{\circ}-70^{\circ}$ dipping to east near the surface rupture and progressively decreasing to $30^{\circ}$ toward the east on the ramp plane (CPC 1974, 1982; Lee 2000b; Lee et al. 2005) (Fig. 2). Using offset of infrastructures (e.g., city streets or concrete fences), Lee et al. (2003a) measured nearly 100 sets of slip vectors along the surface rupture that show the slip direction is in NW from Fengyuan to Wufeng, which is consistent with the GPS data. 
$120^{\circ} 50^{\prime \prime}$

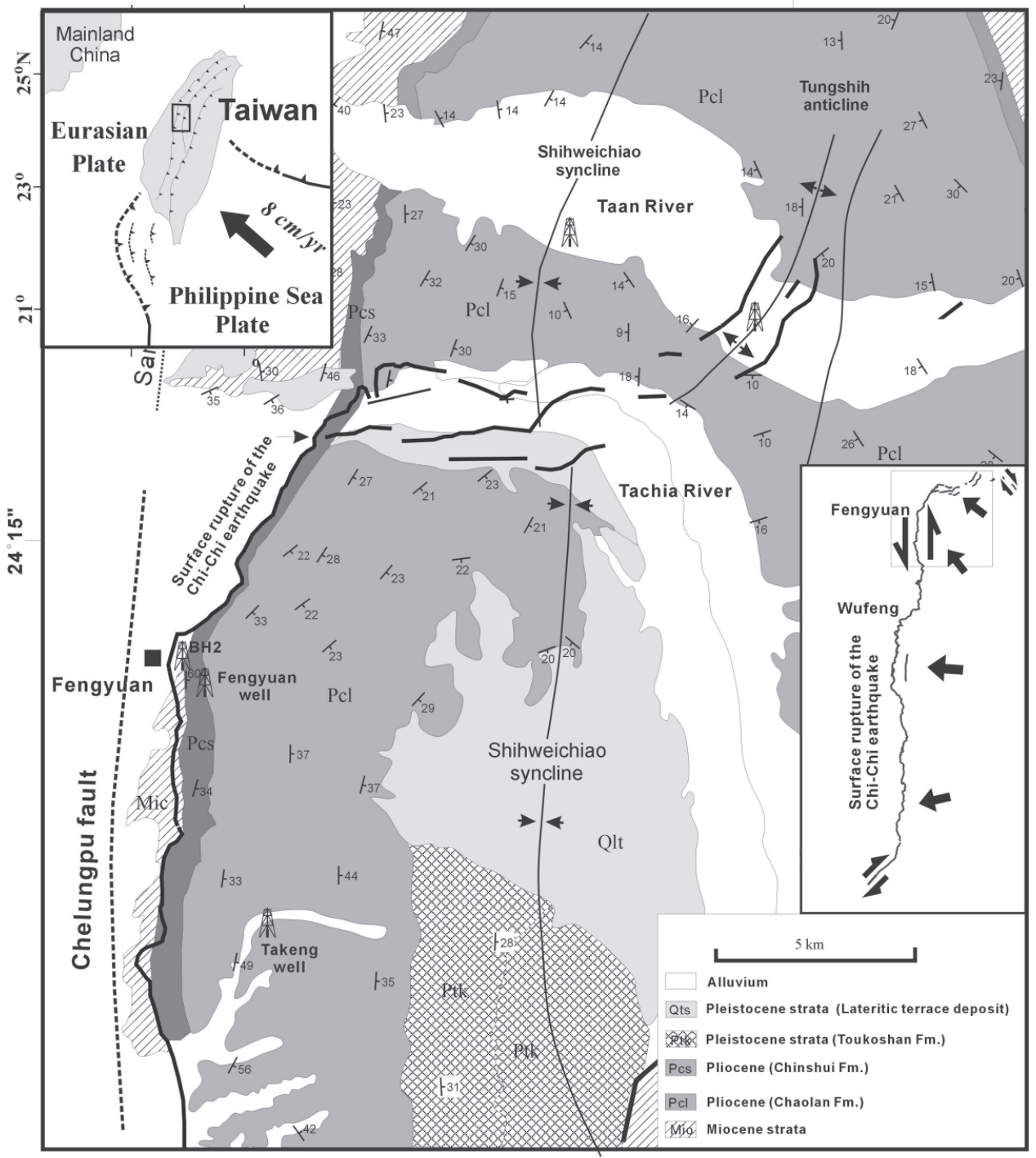

Fig. 2. Geological map (CPC 1974, 1982) and drilling sites at Fengyuan and Takeng area.

\section{THE AREA BALANCING METHOD}

Area balancing method is a classic technique for calculating the depth of a detachment such that the increasing area in front of a measured point will be equal to the depth of detachment multiplied by the known shortening of strata (Dahlstrom 1969). We apply the same concept to estimate the depth of the earthquake slip plane with significant coseismic slip amount. 
We assume, in a given cross section parallel to the regional coseismic slip trend of the thrust block, the area of the section is conserved that means there is no volume loss and no density change. Accordingly, at a given drilling site, the amount of the area horizontally moving along the slip surface $(\mathrm{A} \times \mathrm{C})$ is equal to the area $(\mathrm{D} \times \mathrm{V})$ gained due to uplift next to the site (Lee et al. 2003b; Lee et al. 2005) (Fig. 3). Assuming that the slip of the thrust block is constant from the surface to the depth under shallow depth condition, the total area transferring along the detachment surface can be approximated by the horizontal slip of the thrust block multiplied by the thickness of the block (i.e., the depth of the detachment surface). That means if we know the horizontal displacement, distance from measuring point to the surface rupture, and vertical displacement, we can easily calculate the depth of the earthquake rupture (Fig. 3). Using the GPS data, Johnson and Segall (2004) derived geometry of the Chelungpu fault according the dislocation model. Figure $4 \mathrm{~b}$ shows the horizontal displacement distribution from surface to slip plane according to the results of Johnson and Segall (Johnson and Segall 2004). The horizontal displacement is not the same from surface to slip plane in depth but does not change a lot in the near surface rupture. This supports, to some extend, the assumption that the horizontal displacement is the same from surface to slip plane. We also tested the area balancing method at the Neiwan area (Lee et al. 2005). According to seismic profile and well data, the depth of the Chinshui Shale is about $600 \mathrm{~m}$ at the Neiwan area (Fig. 5b). The Chinshui Shale is the slip plane of the Chi-Chi earthquake. The Neiwan area shows a coseismic folding

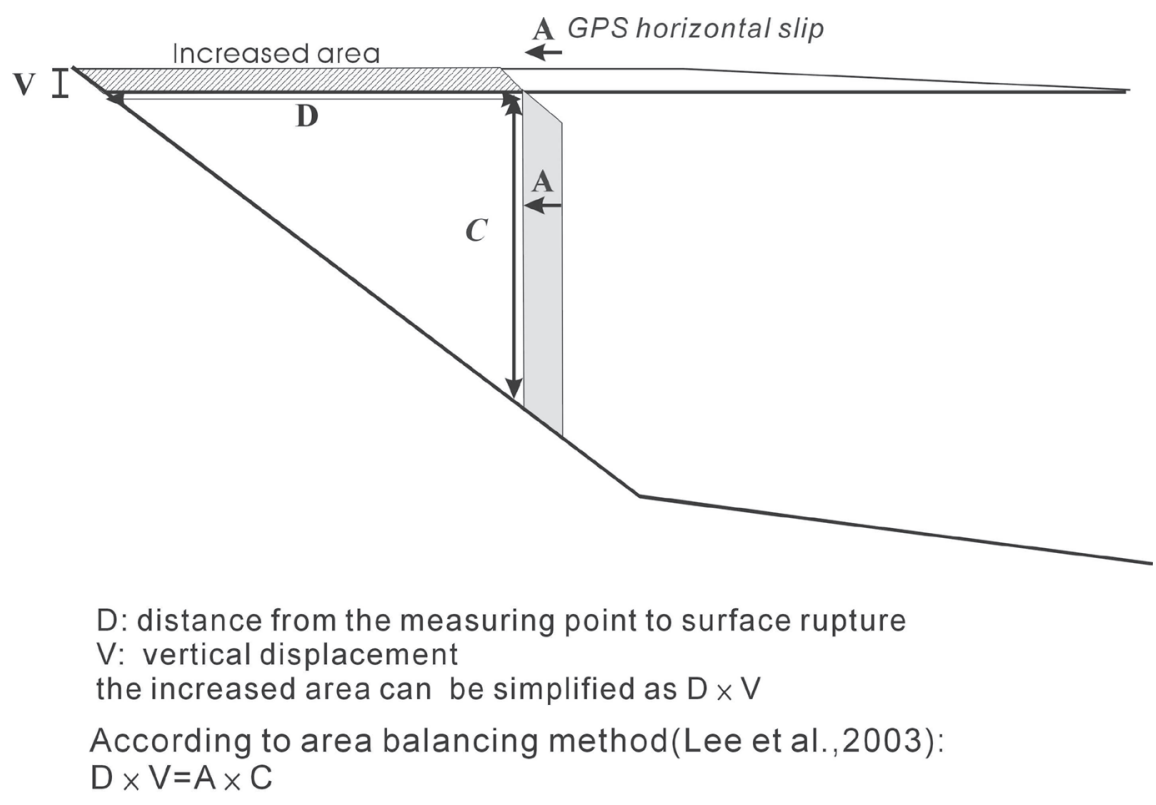

Fig. 3. Schematic map of balancing-cross section method. The increased area is equal to horizontal displacement multiplying with the depth of the earthquake rupture. 
(a)

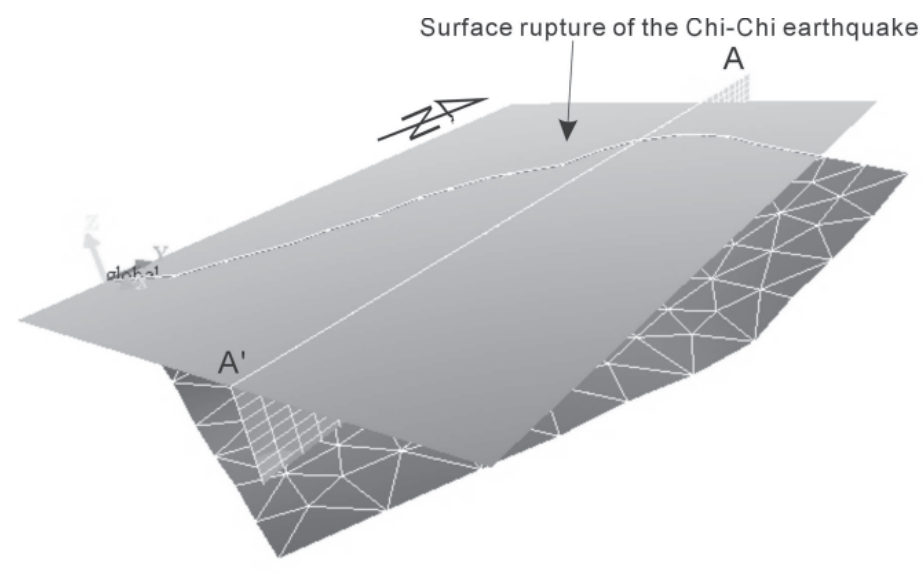

(b)

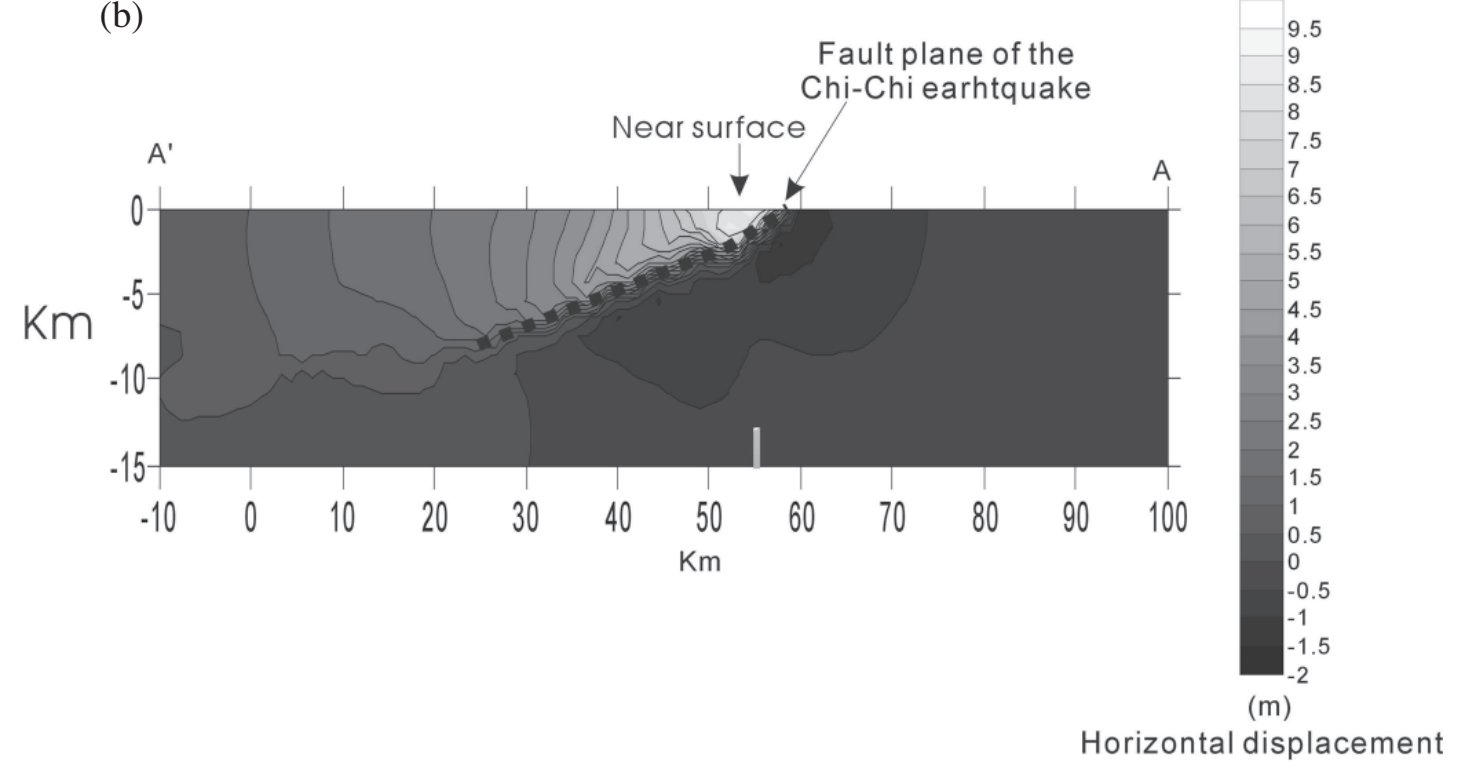

Fig. 4. Horizontal displacement distribution from surface to fault plane. (a) The geometry and slip distribution of the Chi-Chi earthquake is according to Johnson and Segall (2004). The strike of the AA' is parallel to the displacement direction of the northern segment of the Chi-Chi earthquake. (b) The horizontal displacement amount is similar from surface to fault plane, and it progressively decreases away from the surface rupture. We constructed this profile by Poly3D (Thomas 1993). 
structure during the Chi-Chi earthquake. The increased area of the folding structure is about $5970 \mathrm{~m}^{2}$ and the horizontal slip is $10.4 \mathrm{~m}$; therefore we can obtain the depth of the detachment to be about $573 \mathrm{~m}$, which is roughly consistent with the depth indicated from well and seismic profiling (Lee et al. 2005) (Fig. 5). This result indicates the usefulness of the area balancing method.

(a)

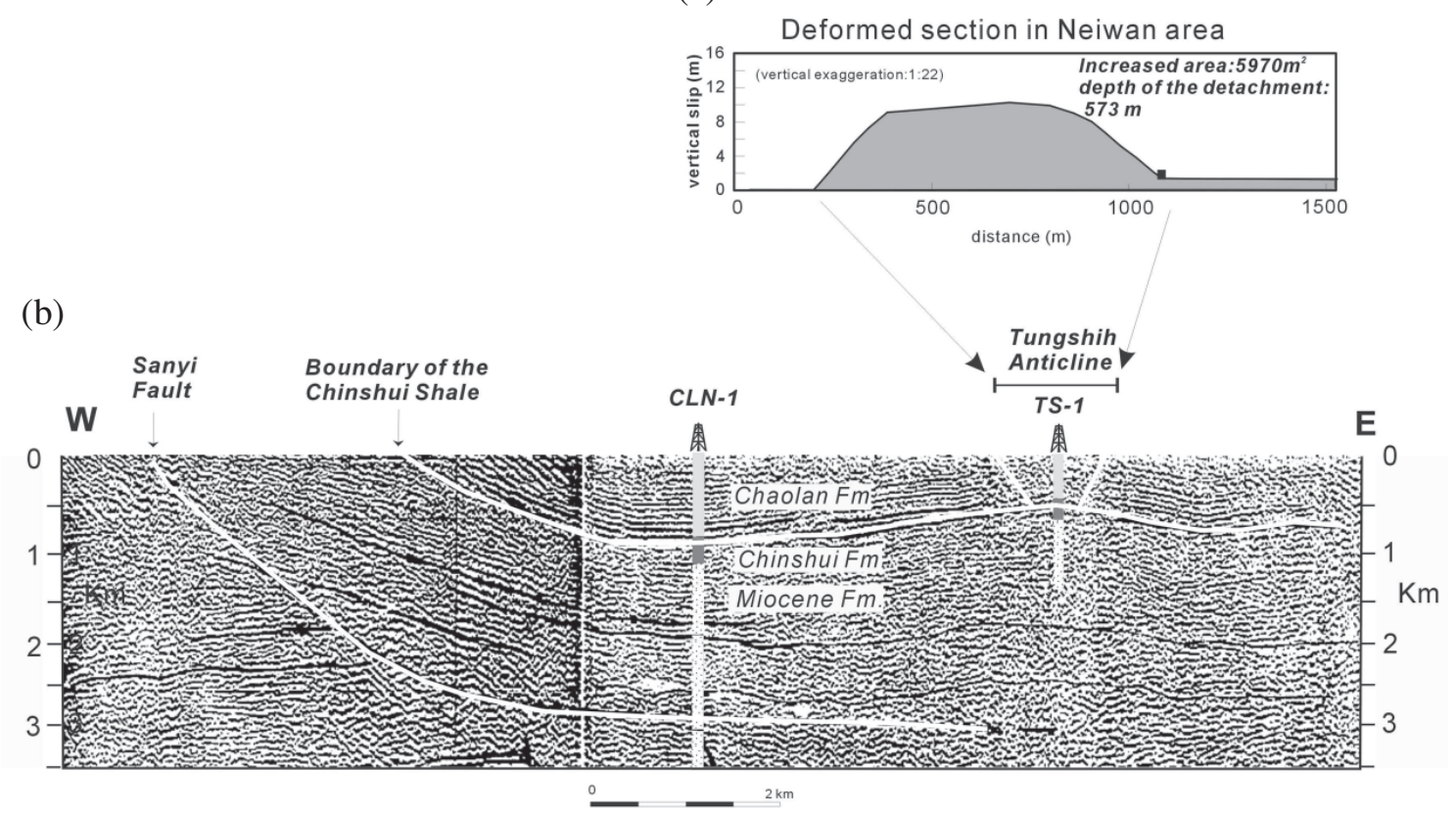

Fig. 5. Depth of the slip plane of the Chi-Chi earthquake under the Neiwan area. (a) Deformation profile in the Neiwan area. The increased area is $5970 \mathrm{~m}^{2}$ and the calculated depth of the Chi-Chi earthquake rupture is $573 \mathrm{~m}$. (b) The seismic profile around the Neiwan area. The location of the profile shows in Fig. 1. The slip plane was along the Chinshui Shale, which is at about $600 \mathrm{~m}$ in depth and this depth is similar to the calculated value.

\section{VERTICAL DISPLACEMENT AROUND THE DRILLING SITE}

While we apply the above area balancing method to estimate the depth of the earthquake slip plane, the vertical displacement is an important factor affecting the accuracy of the measurement. The scarp is about $3-4 \mathrm{~m}$ high around the Fengyuan area according to direct field measurements (CGS 1999; Lee et al. 2003b) and 1: 1000 scale topographic maps along the surface rupture (Fig. 6) (NCREE 2000).

The northern segment of the Chi-Chi earthquake rupture shows a ramp-flat structure and 


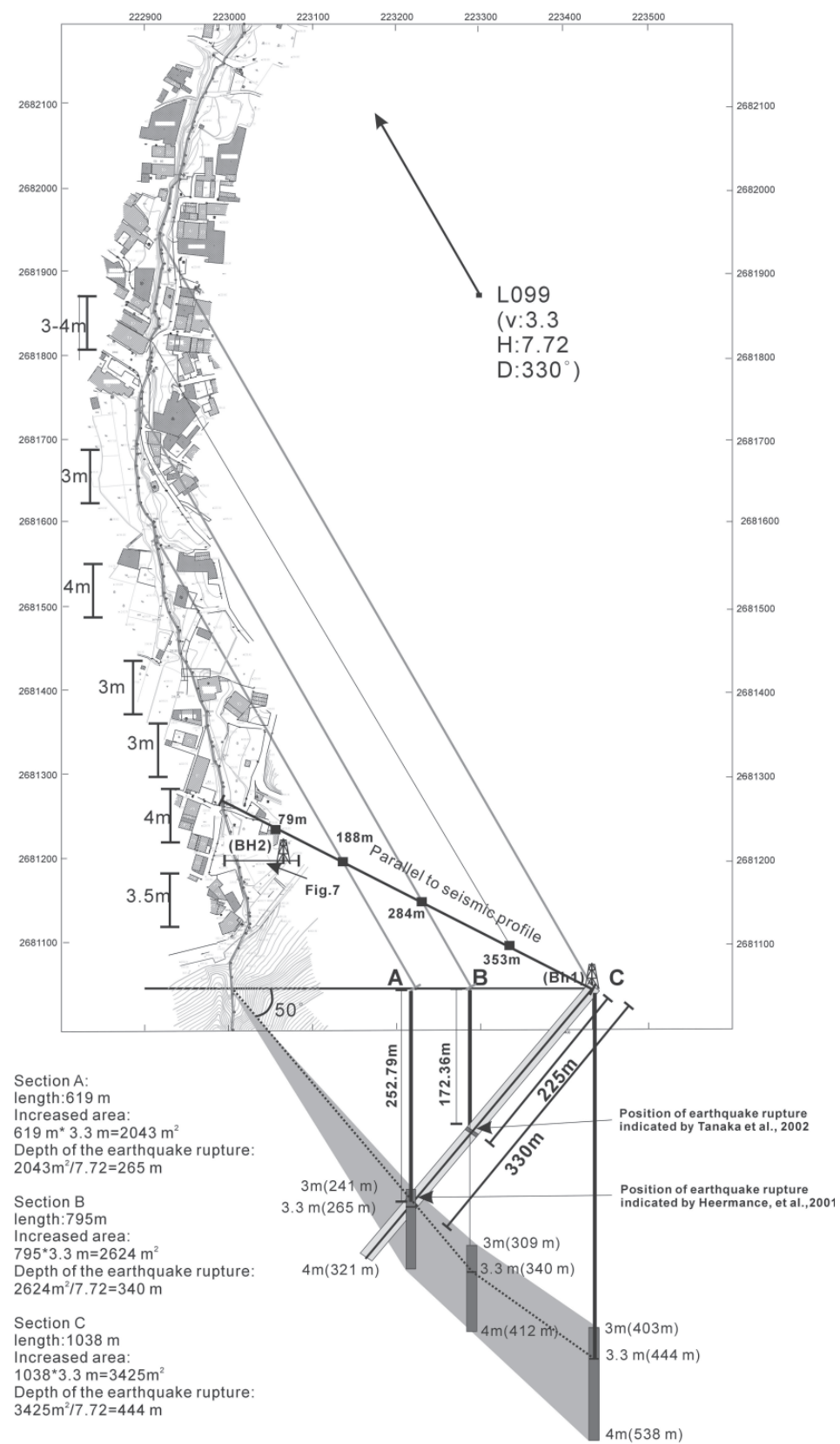

Fig. 6. The vertical displacement is $3-4 \mathrm{~m}$ high along the surface ruptures of the Ch-Chi earthquake. The bottom of figure shows the measuring results of the balancing method and fault geometry. The dotted line is the fault geometry according to $3.3-\mathrm{m}$ vertical displacement. The gray area shows the possible position of the fault plane. 
the Shihweichiao syncline is located on the kink axis of the ramp-flat structure. According to cosesimic GPS data, the vertical displacements are $3-4 \mathrm{~m}$ and $\sim 1 \mathrm{~m}$ high on the ramp and flat structure, respectively (Yu et al. 2001, Yang et al. 2000, Lee et al. 2003a, b; Lee et al. 2005) (Fig. 1). The Fengyuan drilling sites are located on the ramp structure. Therefore, we assumed that the regional vertical displacement from the drilling site to the surface rupture is about $3-4 \mathrm{~m}$, although we have no exact vertical displacement data.

\section{DEPTH OF THE EARTHQUAKE RUPTURE AT FENGYUAN WELL}

The Fengyuan site is about $2.1 \mathrm{~km}$ ENE from Fengyuan city and is about $500 \mathrm{~m}$ to the east of the surface rupture of the Chelungpu fault. It is an inclined borehole dipping $50^{\circ}$ toward the west and the total drilling depth is $455.3 \mathrm{~m}$ (Fig. 6). Detailed core descriptions and drilling conditions have been documented by Tanaka et al. (2002), Hwang et al. (2002), and Heermance et al. (2003). Tanaka et al. (2002) considered that two rupture surfaces were possibly activated by the 1999 Chi-Chi earthquake, one at a $225-\mathrm{m}$ drilling depth and the other at $330 \mathrm{~m}$. The 225-m drilling depth rupture roughly coincides with the boundary of the Chinshui Shale and the Kweichulin Formation and the 330-m drilling depth locates at the Kweichulin Formation (Hwang et al. 2002). Tanaka et al. (2002) considered that the 225-m drilling depth coincides with a shallow seismic profile of high water content. Heermance et al. (Heermance et al. 2003) considered the depth around $330 \mathrm{~m}$ to be a high-density rupture zone that indicated earthquakes rupture.

In order to identify which rupture zone is associated with the Chi-Chi earthquake, we measured the depths of the earthquake rupture in three steps using the area balancing method. First, we projected the 330-m and 225-m drilling depths to the surface giving positions A and B, respectively. Position C was the location of the Fengyuan well (Fig. 6). Second, we made a vertical displacement profile from the drilling site to the surface rupture to calculate the increased area, which is parallel to the displacement direction. The GPS control point, L099, is near the Fengyuan site, and it shows a 7.72-m horizontal displacement in a $330^{\circ}$ direction and a 3.3-m vertical displacement (LSB 2000). Thus, we use $7.72 \mathrm{~m}$ to be the horizontal displacement amount. According to scrap high and vertical displacement of L099 controlling point, we use $3 \mathrm{~m}, 3.3 \mathrm{~m}$ and $4 \mathrm{~m}$ to be the calculated values of the vertical displacement and assume that the vertical displacement is the same across the measured profiles. Thus, the increased area can be simplified as the distance from the surface rupture to the calculated positions multiplied by the vertical displacement. The measured depth of the earthquake rupture in each position is shown in Table 1 and Fig. 6.

The possible depths of the earthquake at position A are $241 \mathrm{~m}, 265 \mathrm{~m}$ and $321 \mathrm{~m}$ according to the 3-m, 3.3-m and 4-m vertical displacements. Figure 6 shows possible depth of the slip plane. It shows that the position of an earthquake rupture at $252.79 \mathrm{~m}$ inferred from Heermance et al. (2003) is located in our estimated depth but the position at $172.36 \mathrm{~m}$ inferred from Tanaka et al. (2002) being unable to fit into our estimated depth. Using the same concept, we can estimate that if the depth at $172.36 \mathrm{~m}$ is the slip plane, then the horizontal slip amount would be $15.2 \mathrm{~m}$ according to a 3.3-m vertical displacement or the vertical displacement would 
Table 1. Depths of the earthquake rupture according different vertical displacements at different positions. A, B, and $\mathrm{C}$ are the measured sections.

\begin{tabular}{|c|c|c|c|}
\hline \multirow{2}{*}{$\begin{array}{c}\text { Vertical } \\
\text { displacement }\end{array}$} & \multicolumn{3}{|c|}{ Length of measuring profile } \\
\cline { 2 - 4 } & $\mathrm{A}: 619 \mathrm{~m}$ & $\mathrm{~B}: 795 \mathrm{~m}$ & $\mathrm{C}: 1038 \mathrm{~m}$ \\
\hline $3 \mathrm{~m}$ & $241 \mathrm{~m}$ & $309 \mathrm{~m}$ & $403 \mathrm{~m}$ \\
\hline $3.3 \mathrm{~m}$ & $265 \mathrm{~m}$ & $340 \mathrm{~m}$ & $444 \mathrm{~m}$ \\
\hline $4 \mathrm{~m}$ & $321 \mathrm{~m}$ & $412 \mathrm{~m}$ & $538 \mathrm{~m}$ \\
\hline
\end{tabular}

be about $6.5 \mathrm{~m}$ based on a $7.22 \mathrm{~m}$ horizontal displacement. These values are not consistent with coseismic displacement of GPS. The result prefers the depth at $252 \mathrm{~m}$ (330-m drilling depth) as being the possible slip plane, which is similar with a depth of $265 \mathrm{~m}$ obtained by assuming the $3.3-\mathrm{m}$ vertical displacement. We thus use the $3.3-\mathrm{m}$ vertical displacement to estimate the geometry of the fault plane. The dip angle is about $37^{\circ}$ from position $\mathrm{C}$ to $\mathrm{B}$ and near $50^{\circ}$ from position B to the surface rupture. Another Chelungpu fault drilling (BH2) is located only $40 \mathrm{~m}$ to the west of the surface rupture and this well penetrates the fault zone at a $50-\mathrm{m}$ depth indicating that the dip angle is $50^{\circ}$ (Lee 2000a) (Fig. 7). This dipping angle coincides with our results confirming the usefulness of the area balancing method in this case.

Tanada et al. (2002) inferred from the shallow seismic profile that the 225-m drilling depth was the position of the earthquake rupture. The problem here being that the drilling direction is in a westward direction, but the seismic profile is in a near $297^{\circ}$ direction (Fig. 8). Therefore, we cannot connect both data directly. In order to accommodate both, we would have to either project the well data in a $297^{\circ}$ direction or project the seismic data in a westward direction. In order to compare our results with the seismic profile, we also measured the depth of the slip plane along the seismic profile by the area balancing method. The black dash line is the fault plane according to the 3.3-m vertical displacement. From a depth of $180 \mathrm{~m}$ to one of $444 \mathrm{~m}$, it shows bedding slip; and from $180 \mathrm{~m}$ to the surface it shows about a $50^{\circ}$ dip angle (Fig. 8).

\section{CONCLUSION AND DISCUSSION}

According to the area balancing method, we suggest that the 330-m drilling depth at Fengyuan well is the position of the Chi-Chi earthquake rupture.

The major problems with using an area balancing method are the accuracy of the vertical and horizontal displacements from the surface to the slip plane. In this paper, we assume that the horizontal displacement is the same from surface to slip plane at depth and the same from the surface rupture to measuring points. The GPS data show that the horizontal displacement decreases progressively from the surface rupture toward the east (Yu et al. 2001) and the changing rate of horizontal displacement parallel to the displacement direction is about 
(a)

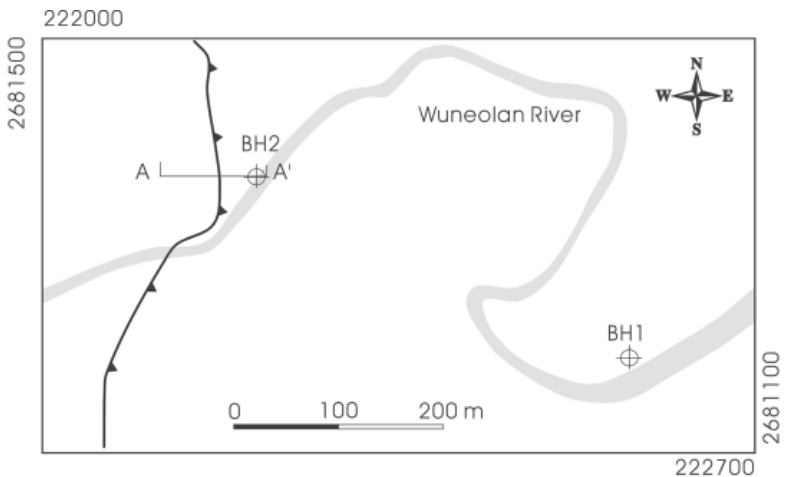

(b)

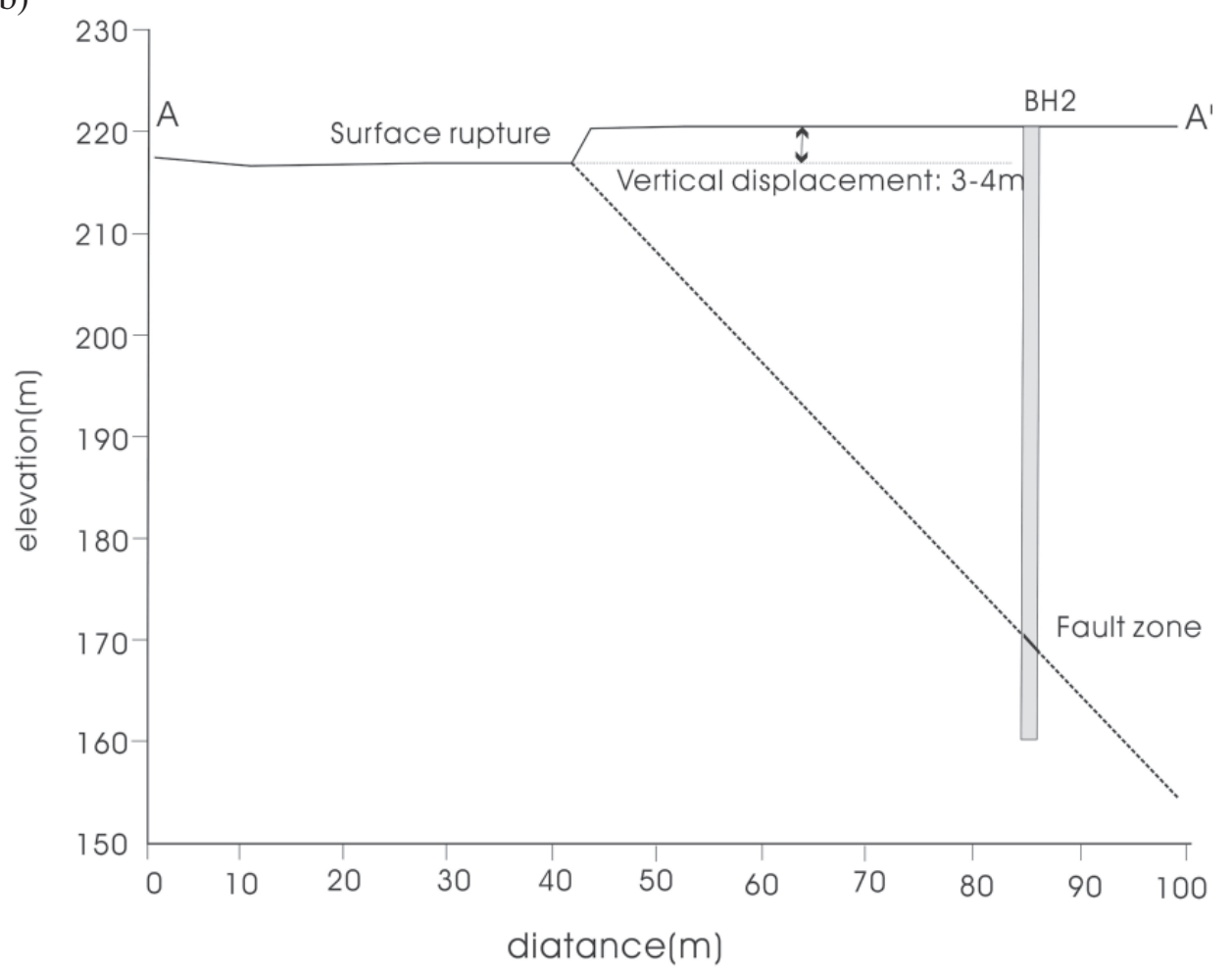

Fig. 7. (a) The wells position of $\mathrm{BH} 1$ and $\mathrm{BH} 2$. (b) The vertical displacement is about $3-4 \mathrm{~m}$ along the $\mathrm{BH} 1$ section and the fault dip angle is near $50^{\circ}$ (Lee et al. 2000). 
(a)

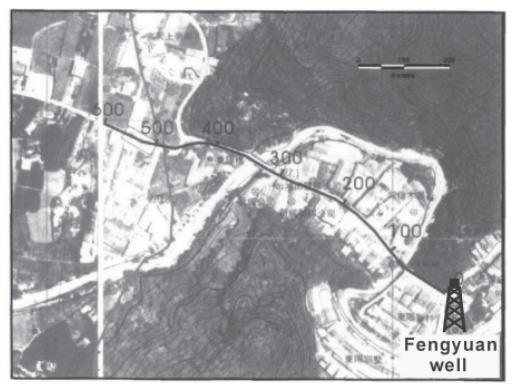

(b)

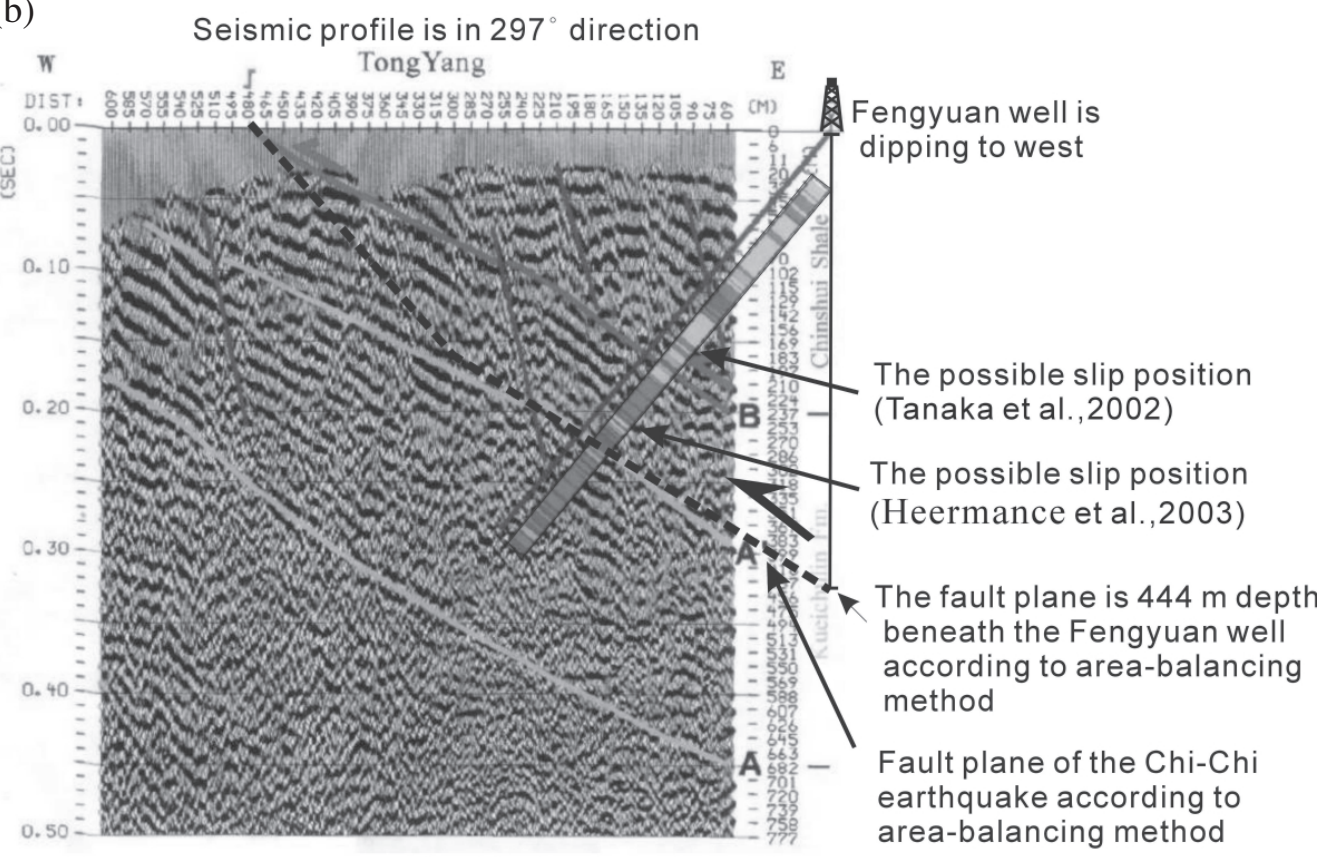

Fig. 8. (a) The position of the shallow seismic profile around Fengyuan site (Wang et al. 2002). (b) The seismic profile is according to Wang et al. 2002. The geometry of fault plane according to the area balancing method with 3.3-m vertical displacement. The black dash line shows the possible fault trace of the Chi-Chi earthquake. The gray color lines show the structures interpreted by Wang et al. (2002).

$10^{-3} \sim 10^{-4}$ indicating that while the measuring profile is short, we can assume the horizontal displacement is the same; but if we want to measure a long profile, we should consider changes in the horizontal displacement. 
Acknowledgments Special thanks are given to colleagues at the Central Geological Survey, R.O.C. for support and their constructive comments on this manuscript. This paper is also finished under the help of the National Science Council of Taiwan, R.O.C. (NSC-91-0472001-003) and Center Geological Survey, MOEA. R.O.C. Critical reviews by Dr. Jian-Cheng Lee and another anonymous reviewer are greatly appreciated and signifcantly improved the paper.

\section{REFERENCES}

CGS, (Central Geological Survey), 1999: Report of the geological survey of the 1999 ChiChi earthquake. Cent. Geol. Surv., Taiwan. (in Chinese)

Chang, S. L., 1971: Subsurface geologic study of the Taichung basin. Petrol. Geol. Taiwan, 8, 21-45.

Chen, Y. G., W. S. Chen, J. C. Lee, Y. H. Lee, C. T. Lee, H. C. Chang, and C. H. Lo, 2001a: Surface Rupture of 1999 Chi-Chi earthquake yields insights on active tectonics of central Taiwan. Bull. Seism. Soc. Am., 91, 977-985.

Chen, W. S., B. S. Huang, Y. G. Chen, Y. H. Lee, C. N. Yang, C. H. Lo, H. C. Chang, Q. C. Sung, N. W. Huang, C. C. Lin, S. H. Sung, and K. J. Lee, 2001b: 1999 Chi-Chi earthquake: A case study on the role for thrust-ramp structures for generating earthquake. Bull. Seism. Soc. Am., 91, 986-994.

Chen, W. S., K. J. Lee, L. S. Lee, Daniel. J. Ponti, C. Prentice, Y. G. Chen, H. C. Chang, and Y. H. Lee, 2004: Slip rate and recurrence interval of the Chelungpu fault during the past 1900 years. Quat. Int., 115-116, 167-176.

Chinese Petroleum Corporation (CPC), 1974: The geological map of Miaoli, Taiwan Petrol. Explor. Div. Plu. CPC, Taiwan, scale $1: 100000$.

Chinese Petroleum Corporation (CPC), 1982: The geological map of Taichung, Taiwan Petrol. Explor. Div. Plu. CPC, Taiwan, scale $1: 100000$.

Dahlstrom, C. D. A., 1969: Balanced cross sections: Canadian J. Earth Sci., 6, 743-757.

Heermance R., Z. K. Shipton, and J. P. Evans, 2003: Fault structure control on fault slip and ground motion during the 1999 rupture of the Chelungpu fault, Taiwan. Bull. Seism. Soc. Am., 93, 1034-1050.

Hwang, S. T., J. C. Wu, J. H. Hung, and H. Tanaka, 2002: Studies of sedimentary faces, stratigraphy, and deformation structures of the Chelungpu fault on cores from drilled wells in Fengyuan and Nantou, Central Taiwan. Terr. Atmos. Ocean. Sci., 13, 253-278.

Johnson, K. M., and P. Segall, 2004: Imaging the ramp-decollement geometry of the Chelungpu fault using coseismic GPS displacements from the 1999 Chi-Chi, Taiwan earthquake. Tectophys., 378, 123-139.

Lee, C. T., 2000a: The report of HQ continuing sampling of the Chelungpu drilling project. Nat. Cent. Univ.

Lee, J. F., 2000b: Geological map of Tungshih. Cent. Geol. Surv., Taiwan, scale 1: 50000. 
Lee, Y. H., W. Y. Wu, T. S. Shih, S. T. Lu, M. L. Meng, and H. C. Chang, 2000: Deformation mechanism of the northern ending surface ruptures of the Chi-Chi earthquake. Special Publ. Cent. Geol. Surv., 12, 19-39. (in Chinese with English Abs.)

Lee, Y. H., M. L. Hsieh, S. T. Lu, T. S. Shih, W. Y. Wu, Y. Sugiyama, T. Azuma, and Y. Kariya, 2003a: Slip vectors of the surface rupture of the 1999 Chi-Chi earthquake, western Taiwan. J. Struct. Geol., 25, 1917-1931.

Lee, Y. H., S. T. Lu, T. S. Shih, and W. Y. Wu, 2003b: Comment on "A vertical exposure of the 1999 surface rupture of the Chelungpu fault at Wufeng, western Taiwan: Structural and paleoseismic implications for an active thrust fault". Bull. Seism. Soc. Am., 93, 963-968.

Lee, Y. H., S. T. Lu, T. S. Shih, M. L. Hsieh, and W. U. Wu, 2005: Structures associated with the northern end of the 1999 Chi-Chi earthquake rupture, central Taiwan: implications for seismic hazard assessment. Bull. Seism. Soc. Am., 95, 471-485.

LSB, 2000: Report of the basic controlling point measurement after the Chi-Chi earthquake. Land Survey Bureau, Taiwan.

NCREE, 2000: Topographic map along the surface rupture of the Chi-Chi earthquake, National Center for Research on Earthquake Engineering, Taiwan, scale 1: 1000.

Tanaka, H., C.Y. Wang, W. M. Chen, A. Sakaguchi, K. Ujiie, and M. Ando, 2002: Initial science report of shallow drilling penetrating into the Chelungpu Fault Zone, Taiwan. Terr. Atmos. Ocean. Sci., 13, 227-251.

Thomas A. L., 1993: POLY3D: A three-dimensional, polygonal element, displacement discontinuity boundary element computer program with applications to fractures, faults, and cavities in the earth's crust. Master Thesis, Stanford Univ.,62 pp.

Wang, C. Y., C. H. Chang, and H. Y. Yen, 2000: An interpretation of the 1999 Chi-Chi earthquake in Taiwan based on the thin-skinned thrust model. Terr. Atmos. Ocean. Sci., 11, 609-630.

Wang, C. Y., C. L. Li, F. C. Su, M. T. Leu, M. S. Wu, S. H. Lai, and C. C. Chern, 2002: Structural mapping of the 1999 Chi-Chi earthquake fault, Taiwan by seismic reflection methods. Terr. Atmos. Ocean. Sci., 13, 211-226.

Yang, M., R. J. Rau, J. Y. Yu, and T. T. Yu, 2000: Geodetically observed surface displacements of the 1999 Chi-Chi, Taiwan, earthquake. Earth Planets Space, 52, 403-413.

Yu, S. B., L. C. Kuo, Y. J. Hsu, H. H. Su, C. C. Liu, C. S. Hou, J. F. Lee, T. C. Lai, C. L. Liu, T. F. Tseng, C. S. Tsai, and T. C. Shin, 2001: Preseismic deformation and coseismic displacements associated with the 1999 Chi-Chi, Taiwan, earthquake. Bull. Seism. Soc. Am., 91, 995-1012.

Lee, Y. H., S. T. Lu, and T. S. Shih, 2006: Area balancing method as a useful tool to estimate the depth of the Chi-Chi earthquake rupture at the Fengyuan well. Terr. Atmos. Ocean. Sci., 17, 489-502. 